\title{
Real-world effectiveness of natalizumab treatment in patients with relapsing multiple sclerosis in Argentina and Chile
}

\author{
Efectividad en el mundo real del tratamiento con Natalizumab para pacientes con \\ esclerosis múltiple recurrente en Argentina y Chile \\ Maria Celica YSRRAELIT', Alejandro CARIDE², Vladimiro SINAY³, Mario RIVERA KINDEL4, \\ Mario Javier HALFON ${ }^{5}$, Liliana PATRUCCO ${ }^{6}$, Raul PIEDRABUENA', Vanina Eleonor DIAZ ARAGUNDE ${ }^{8}$
}

\begin{abstract}
Background: The real-world effectiveness of natalizumab in people with relapsing multiple sclerosis (PwRMS) in Argentina and Chile has not been reported. Objective: To evaluate the effectiveness of natalizumab treatment in PwRMS in Argentina and Chile, in clinical practice. Methods: We conducted a multicenter retrospective and observational study. We reviewed the medical records of PwRMS who had been treated with natalizumab for at least one year, without any interruption in MS treatment that lasted more than 12 weeks. We analyzed changes in annualized relapse rate (ARR), Expanded Disability Status Scale (EDSS) score and magnetic resonance imaging (MRI). Results: We enrolled 117 PwRMS treated with natalizumab. Natalizumab treatment was associated with a significant reduction in ARR from baseline after one year and two years of treatment (from 1.97 to 0.06 and 0.09 respectively; $p<0.01$ at each time point). From baseline, EDSS scores were reduced by 0.71 and 0.73 points at one and two years, respectively $(p<0.01)$. No worsening of disability was observed in 82.9 and $67.5 \%$ of PwRMS at one and two years, respectively. The improvement in disability was $44.4 \%$ at one year and $39.3 \%$ at two years. During natalizumab treatment, the number of relapse-related hospitalizations was significantly reduced ( $p<0.01)$. MRI lesions (new/ enlarging T2 or gadolinium-enhancing) were significantly reduced, compared with baseline. No evidence of disease activity was observed in $65 \%$ at two years of natalizumab treatment. Conclusions: Natalizumab significantly reduced disease activity in PwRMS in Argentina and Chile, in clinical practice. Natalizumab also decreased the number of hospitalizations compared with pre-natalizumab treatment.
\end{abstract}

Keywords: Observational Study; Effectiveness; Multiple Sclerosis; Natalizumab; Latin America.

\footnotetext{
${ }^{1}$ Institute for Neurological Research Dr Raul Carrea, FLENI, Neurology Department, Buenos Aires, Argentina.

${ }^{2}$ Hospital Aleman, Department of Neuroscience, Neuroimmunology Unit, Buenos Aires, Argentina.

${ }^{3}$ Fundación Favaloro Hospital, Buenos Aires, Argentina.

${ }^{4}$ Clínica Dávila, Recoleta, Región Metropolitana, Chile.

${ }^{5}$ British Hospital of Buenos Aires, Buenos Aires, Argentina.

${ }^{6}$ Hospital Italiano de Buenos Aires, Buenos Aires, Argentina.

${ }^{7}$ Clínica Universitaria Reina Fabiola, Servicio de Neurología, Córdoba, Argentina.

${ }^{8}$ Biogen S.R.L., Buenos Aires, Argentina.

Maria Celica YSRRAELIT (D) https://orcid.org/0000-0003-0846-5825; Alejandro CARIDE (D) https://orcid.org/0000-0001-5228-1404;

Vladimiro SINAY (D) https://orcid.org/0000-0001-8054-104X; Mario RIVERA KINDEL (D) https://orcid.org/0000-0001-6464-5252;

Mario Javier HALFON (D) https://orcid.org/0000-0001-7289-8137; Liliana PATRUCCO (iD https://orcid.org/0000-0003-0207-8146;

Raul PIEDRABUENA (D) https://orcid.org/0000-0002-2980-5334; Vanina Eleonor DIAZ ARAGUNDE (D) https://orcid.org/0000-0002-7261-7355

Correspondence:Vanina Eleonor Diaz Aragunde; E-mail:vanina.diazaragunde@biogen.com

Conflict of interest: MCY has received personal compensation for consulting, serving on a scientific advisory board, speaking, professional travel/ accommodation stipends or other activities with Merck, Biogen, Genzyme, Novartis, Roche and Bayer. AC has received personal compensation for consulting, serving on a scientific advisory board, speaking, professional travel/accommodation stipends or other activities with Biogen, Genzyme, Merck-Serono, Novartis, Teva, Roche and Bayer. VS has received personal compensation for consulting, serving on a scientific advisory board, speaking, professional travel/accommodation stipends or other activities with Bayer, Biogen, Genzyme, Merck, Novartis, Roche, Biosidus, Gador, Tuteur and Raffo/Asofarm. MER has received personal compensation for consulting, serving on a scientific advisory board, speaking, professional travel/accommodation stipends or other activities with Biogen, Novartis, Roche and Sanofi Genzyme. MJH has received personal compensation for consulting, serving on a scientific advisory board, speaking, professional travel/accommodation stipends or other activities with Biogen, Merck Argentina, Roche, Gador, Novartis and Genzyme Argentina. LBP has received personal compensation for consulting, serving on a scientific advisory board, speaking, professional travel/accommodation stipends or other activities with Biogen, Genzyme, Merck, Novartis and Roche. RP has received personal compensation for consulting, serving on a scientific advisory board, speaking, professional travel/accommodation stipends or other activities with Merck, Biogen, Roche, Teva, Genzyme and Novartis. VDA serves as a Medical Science Liaison, Medical Affairs, for Biogen S.R.L., Buenos Aires, Argentina.
}

Authors' contributions: VDA: contributed substantially to the conception and design of the study. All authors contributed equally to the collection, analysis, and interpretation of data; to the writing and critical review of the manuscript; and to the approval of the final version to be published.

Support: This study was supported by Biogen S.R.L. Argentina. Biogen reviewed the manuscript and provided feedback on the manuscript. However, the authors had full editorial control over the manuscript and provided their final approval for all content.

Received on July 02, 2020; Received in its final form on August 13, 2020; Accepted on September 01, 2020. 
Antecedentes: La efectividad de Natalizumab en personas con esclerosis múltiple recurrente (PwRMS) en Argentina y Chile no se ha reportado. Objetivo: Evaluar la efectividad del tratamiento con Natalizumab en PwRMS en Argentina y Chile en la práctica clínica. Métodos: Estudio multicéntrico, retrospectivo y observacional. Revisamos los registros médicos de PwRMS que fueron tratados con Natalizumab al menos 1 año, sin interrupción de tratamiento para EM durante más de 12 semanas. Analizamos los cambios en la tasa anualizada de recaídas (ARR), escala de discapacidad expandida (EDSS) y resonancia magnética (MRI). Resultados: Se incluyeron 117 PwRMS. El tratamiento con Natalizumab se asoció con una reducción significativa de la tasa anualizada de recaídas (ARR) cada 1 y 2 años (de 1.97 a 0.06 y 0.09 , respectivamente; $p<0.01$ en ambos casos). El EDSS se redujo 0,71 y 0,73 puntos al año 1 y 2 , respectivamente ( $p<0,01$ ). No se observó empeoramiento del EDSS en 82,9 y 67,5\% de los PWRMS al año 1 y 2, respectivamente. La mejoría del EDSS fue 44,4 y $39,3 \%$ al año 1 y 2, respectivamente. El número de hospitalizaciones se redujo significativamente ( $p<0,01)$. Las lesiones en MRI (nuevas/ agrandadas en T2 o con realce con gadolinio) se redujeron significativamente en comparación con el valor basal. No se observó evidencia de actividad de la enfermedad en el 65\% de los PwRMS a 2 los años. Conclusiones: Natalizumab redujo significativamente la actividad de la enfermedad en PwRMS de Argentina y Chile en la práctica clínica. Además, disminuyó el número de hospitalizaciones comparado con el tratamiento previo.

Palabras clave: Estudio Observacional; Efectividad; Esclerosis Múltiple; Natalizumab; América.

\section{INTRODUCTION}

Multiple sclerosis (MS) is an inflammatory and neurodegenerative disease of the central nervous system (CNS) with estimated prevalences of 38.2 and 5.7 per 100,000 inhabitants in the city of Buenos Aires, Argentina, and in Chile, respectively ${ }^{1,2,3}$. MS is the leading cause of non-traumatic neurological disability in young adults worldwide ${ }^{1}$.

Natalizumab (Tysabri ${ }^{\oplus}$, Biogen) is a humanized monoclonal antibody (an $\alpha 4$ integrin antagonist) that is indicated for treating people with relapsing multiple sclerosis (PwRMS) who have a poor response to first-line disease-modifying therapies (DMTs), and is indicated for patients who are treatment-naïve and present aggressive $\mathrm{MS}^{4,5}$.

The pivotal randomized controlled studies AFFIRM and SENTINEL provided evidence of the efficacy of natalizumab for its use in PwRMS ${ }^{4,5}$. In the phase III AFFIRM study $^{4}$, natalizumab reduced the sustained progression of disability by $42 \%$ at two years and the relapse rate by $68 \%$ at one year. In the SENTINEL study ${ }^{5}$, the combination of natalizumab and interferon $\beta 1$ a reduced the sustained progression of disability by $24 \%$ at two years and the relapse rate by $54 \%$ at one year, in comparison with interferon $\beta$ la.

Several large observational studies in many countries of the European Union and also in the United States (US) have corroborated the effectiveness of natalizumab in real-world clinical practice ${ }^{6,78}$. Natalizumab has been commercially available in Argentina and Chile since 2010 and 2011, respectively. However, the effectiveness of natalizumab in clinical practice has not previously been studied in Argentina and Chile. Given the few data in our region, we aimed to evaluate the effectiveness of natalizumab in clinical practice in Argentina and Chile through collection of data on demographics, frequency of relapse-related hospitalizations, clinical observations and magnetic resonance imaging (MRI) from clinical records of PwRMS treated with natalizumab.

\section{METHODS}

We conducted a multicenter, observational and retrospective study on data at 18 clinics in Argentina and Chile between May 2017 and February 2018. We reviewed all medical record databases of PwRMS, in accordance with the validated 2010 McDonald criteria ${ }^{1}$, on patients who were treated with natalizumab for at least one year, without any interruption in MS treatment that lasted more than 12 weeks. No data about adherence was obtained.

This study was approved by the local ethics committee of each participating center and oral or written informed consent was obtained from all participants. The study was conducted in accordance with the Declaration of Helsinki and Good Clinical Practice guidelines.

\section{Assessment and endpoints}

For each patient, an ad hoc questionnaire was filled out in a single database that encompassed all the data from all the participating centers in Argentina and Chile and which included demographic, clinical and MRI data, as well as the information concerning natalizumab therapy.

Data collection included demographics (age and gender); clinical background and DMT use; incidence of relapses and relapse-related hospitalizations (before and after treatment with natalizumab compared with baseline [one year prior to natalizumab use] and at one year and two years after the start of natalizumab use), disability measured by EDSS score $^{9}$ (at baseline [last EDSS score before the start of natalizumab use], at one year [12-15 months] and at two years [24-27 months]); number of T1, T2 and gadolinium-enhancing $(\mathrm{Gd}+)$ lesions on MRI (at baseline [last MRI before the start of natalizumab use], between 6 and 12 months and between 18 and 24 months after the start of natalizumab use); and occurrence of a situation of no evidence of disease activity (NEDA; at 2 years after the start of natalizumab use).

The primary endpoint was whether there was a reduction in annualized relapse rate (ARR) during treatment with 
natalizumab (one year and two years) compared with the baseline (one year before the start of treatment with natalizumab), including the proportions of relapse-free patients at one year and two years. The secondary endpoints included measurements of MS disease activity such as MRI parameters and changes in EDSS score, number of relapse-related hospitalizations and overall NEDA ${ }^{10}$.

Relapses were defined as patient-reported or objectively observed events typical of a current or historical acute inflammatory demyelinating event in the CNS, with a duration of at least 24 hours, in the absence of fever or infection ${ }^{1}$. New or recurrent neurological symptoms which occurred within 30 days of the onset of another relapse were considered to be part of the same relapse ${ }^{1}$. Worsening of disability was defined as any increase in EDSS score from baseline and improvement of disability was defined as any decrease in EDSS score from baseline. Overall NEDA was analyzed post hoc and was defined as follows ${ }^{10}$ : no increase in EDSS score, no relapses, no new $\mathrm{Gd}+$ and/or new/enlarging $\mathrm{T} 2$ lesions between baseline and two years. EDSS and MRI scans were evaluated by neurologists with expertise in MS care. To reduce the risk of entry error with EDSS score reporting, the electronic case report form calculated an EDSS score based on the Kurtzke FS $^{9}$ and ambulation scores that were entered. Because this was a retrospective multicenter study, MRIs were performed using different machines.

\section{Statistical analyses}

Continuous data were expressed as means and standard deviation $( \pm \mathrm{SD})$, median, maximum and minimum values. The categorical data were expressed as proportions. The Kolmogorov-Smirnov test was used to evaluate the normal distribution of variables $(\mathrm{p}<0.001)$. Changes in the ARR and MRI were analyzed using the Wilcoxon matched-pair signed-rank test and McNemar test on paired proportions, as appropriate. Poisson distribution and negative bimodal regression models were used to determine whether there was an association between predictor variables and the incidence rate ratio (IRR) of relapses at two years. Based on the data of the TOP study ${ }^{8}$, a reduction of $80 \%$ in ARR would be expected to be observed at two years after the start of natalizumab use. Assuming a data loss rate of $20 \%$, at least 100 patients would be needed to provide $95 \%$ power to detect an $80 \%$ decrease in ARR, based on a simulated result (determination of sample size). Statistical analyses were performed using the STATA 12.0 software (StataCorp TX, US). For all the analyses, the significance level was established as $\mathrm{p}<0.05$.

\section{RESULTS}

We enrolled 117 PwRMS who were being treated with natalizumab. At baseline, $59.8 \%$ were female with a mean age of 35.4 years $( \pm 10.4)$ and a median MS duration before starting natalizumab of 36 months (IQR: 11-84). Prior DMT use was reported by $75.1 \%$ of the PwRMS. As shown in Figure 1, most patients had started their MS treatment with injectable interferons (IFN) (58 out of 87 patients) or glatiramer acetate (22 out of 87 patients). The demographic data and clinical features at baseline are summarized in Table 1.

\section{Endpoints}

\section{Relapses and hospitalizations}

At baseline, the patients had a mean ARR of 1.97 (95\% confidence interval [95\%CI] 1.75-2.20). As shown in Figure 2, natalizumab treatment was associated with a significant reduction in ARR from baseline after one year and two years of treatment (from 1.97 to 0.06 and 0.09 respectively; $\mathrm{p}<0.01$ at each time point).

The proportion of patients free from relapses was significantly higher after one year $(93.9 \%$; 95\%CI, 87.9-97.5; $\mathrm{p}<0.01)$ and two years (92.9\%; 95\%CI, 86.0-97.1; p<0.01) of natalizumab treatment, in comparison with the year before starting natalizumab treatment (7.7\%; 95\%CI, 3.6-14.1). In the year before starting natalizumab use, 83 out of 117 patients had experienced relapse-related hospitalizations (Table 1). Natalizumab treatment reduced the number of relapserelated hospitalizations to one occurrence at one year $(n=114)$ and three occurrences at two years $(n=98)$, which was a significant $(\mathrm{p}<0.01)$ reduction in each case. As shown in Table 2, no association between predictor variables and the IRR of relapses at two years was observed after applying negative binomial regression analysis.

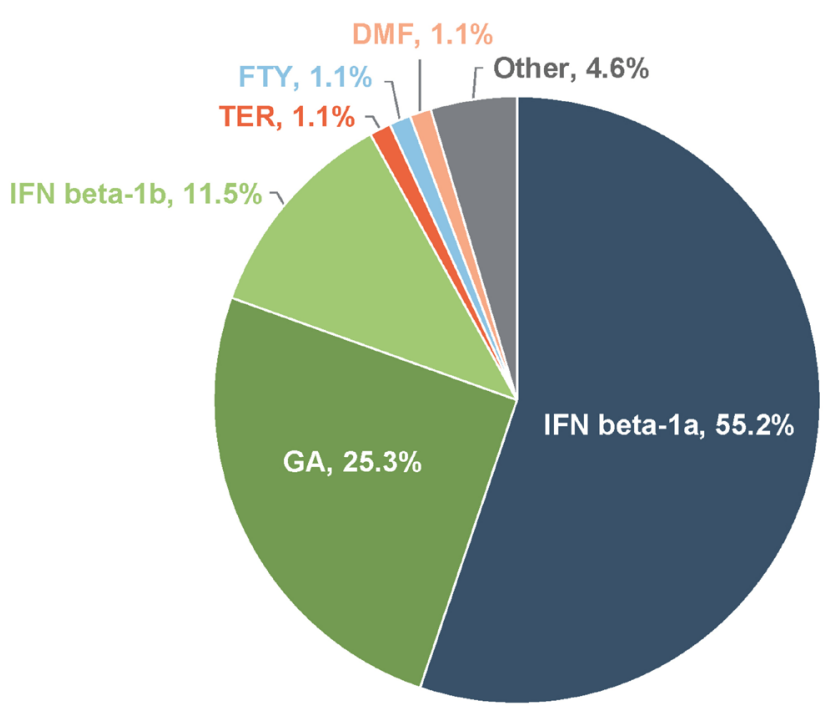

GA: glatiramer acetate; INF $\beta 1 \mathrm{a}$ : interferon $\beta 1 \mathrm{a}$; INF $\beta 1 \mathrm{~b}$ : interferon $\beta 1 \mathrm{~b}$ TER: teriflunomide; FTY: fingolimod; DMF: dimethyl fumarate.

Figure 1. Initial disease-modifying therapy used by patients who reported prior disease-modifying therapy use $(n=87)$. 
Table 1. Baseline clinical characteristics of the study population.

\begin{tabular}{|c|c|}
\hline Characteristic & $\begin{array}{l}\text { Patients with } \\
\text { characteristic } \\
\quad(n=117)\end{array}$ \\
\hline Female, n (\%) & $70(59.8)$ \\
\hline Age mean $( \pm S D)$, years & $35.4( \pm 10.4)$ \\
\hline $\begin{array}{l}\text { Disease duration prior to diagnosis, median } \\
\text { (range), months }\end{array}$ & $36(11-84)$ \\
\hline DMT use prior to natalizumab, n (\%) & $87(75)^{a}$ \\
\hline Immunosuppressant use prior to natalizumab, n (\%) & $7(8.1)^{b}$ \\
\hline EDSS, mean ( $\pm S D$ ) & $3.77( \pm 1.84)$ \\
\hline Relapses in year prior to natalizumab, mean ( \pm SD) & $2.0( \pm 1.2)$ \\
\hline $\begin{array}{l}\text { Relapse-related hospitalizations in previous } \\
\text { year, mean }( \pm S D)\end{array}$ & $1.54( \pm 0.85)^{c}$ \\
\hline \multicolumn{2}{|l|}{ Patients with MRI lesions, $n(\%)^{d}$} \\
\hline T1 lesions & $94(83.2)$ \\
\hline T2 lesions & $114(99.1)$ \\
\hline Gd+ lesions & $73(63.5)$ \\
\hline \multicolumn{2}{|l|}{ MRI lesions per patients, mean ( \pm SD)e } \\
\hline T1 lesions & $6.8( \pm 3.3)$ \\
\hline T2 lesions & $18.5( \pm 8.7)$ \\
\hline Gd+ lesions & $2.7( \pm 3.3)$ \\
\hline
\end{tabular}

SD: standard deviations, EDSS: Expanded Disability Status Scale, DMT: disease-modifying therapy, MRI: magnetic resonance imaging, Gd+: gadolinium-enhancing. $n=116^{a} ; n=87^{b} ; 83$ patients were hospitalized due to relapsec; data on T1,T2 and Gd+ lesions were available for 113,115 and 115 patients, respectivelyd; data on T1, T2 and Gd+ lesions available for 94, 109 and 115 patients, respectively.

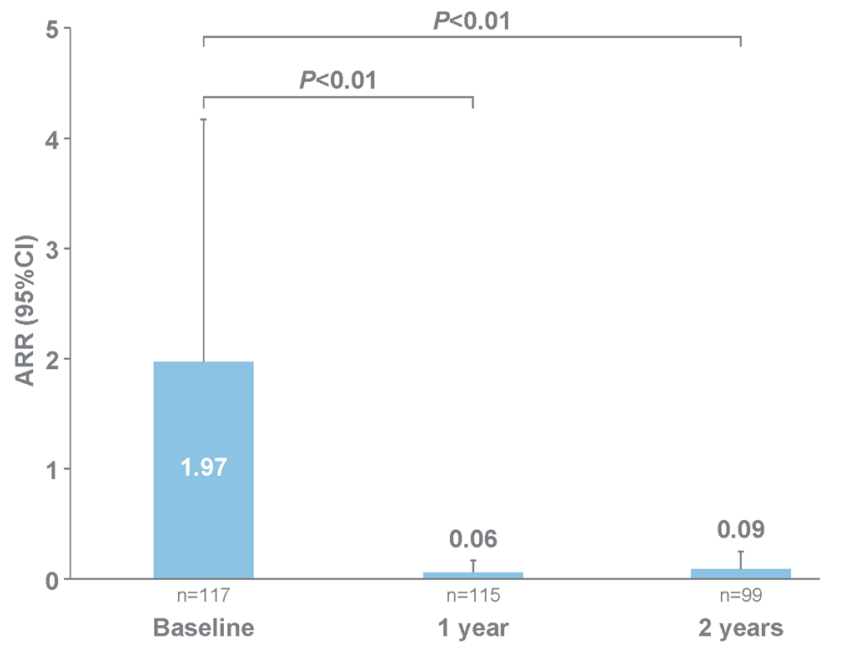

P values based on Wilcoxon matched-pair signed-rank test.

Figure 2. Mean annualized relapse rate in study population at baseline, one year and two years.
Table 2. Patients who became free from clinical and radiological disease activity over two years of natalizumab treatment.

\begin{tabular}{cc}
\hline Assessment* & $\begin{array}{c}\text { Patients without } \\
\text { disease activity at } 2 \\
\text { years } \mathrm{n} / \mathrm{N}(\%)\end{array}$ \\
\hline
\end{tabular}

Clinical assessment

No increase in EDSS score

$77 / 95(81.1)$

Free from relapse over 2 years

$87 / 99(87.9)$

MRI assessment

No new Gd+ lesions over 2 years

90/98 (91.8)

No new/newly enlarging T2 lesions

$79 / 90(87.8)$

Overall NEDA

$57 / 87(65.5)$

EDSS: Expanded Disability Status Scale, MRI: magnetic resonance imaging, Gd+: gadolinium-enhancing, NEDA: no evidence of disease activity. *All assessments were for the interval between baseline and two years. Proportions represent number of patients meeting specified criteria divided by total number of patients with data available at baseline, one year and two years. Patients with overall NEDA were defined as those free from disease activity, as assessed through the four clinical and radiological criteria above.

\section{Disability}

From baseline, the mean EDSS scores were reduced by 0.71 points $(95 \% \mathrm{CI} 0.46-0.96)$ at one year and 0.73 points (95\%CI 0.43-1.03) at two years, as illustrated in Figure 3.

The proportion of the PwRMS with worsening of disability was $15.3 \%$ at one year and $18.9 \%$ at two years. The proportion of the PwRMS with improvement of disability was $46.8 \%$ at one year and $48.4 \%$ at two years, as illustrated in Figure 4.

\section{Magnetic resonance imaging}

At baseline, 94 out of 113 (83.2\%), 114 out of 115 (99.1\%) and 73 out of 115 (63.5\%) of the PwRMS had T1, T2 and Gd+ lesions, respectively (Table 1). As shown in Figure 5, at one year and two years the proportion of the PwRMS treated with natalizumab who still presented Gd+ lesions was significantly lower, compared with baseline (baseline: 73 out of 115 [63.5\%]; one year: 7 out of 114 [6.1\%]; and two years: 8 out of 98 [8.2\%]; $<<0.01$ at each time point), as assessed by the McNemar test on paired proportions. After one year of natalizumab treatment, new $\mathrm{T} 1$ and $\mathrm{T} 2$ lesions were observed in 2.9 and $10.0 \%$ of the patients, respectively. After two years of treatment, 2.2 and $6.3 \%$ of the PwRMS had new T1 and $\mathrm{T} 2$ lesions, respectively.

\section{No evidence of disease activity}

In total, $65.5 \%$ of the PwRMS met the criteria for overall NEDA between baseline and two years (Table 2). Between baseline and two years, $81.1 \%$ of the patients had no increase in EDSS score and $87.9 \%$ of the patients were relapse-free. Over the same span, $91.8 \%$ of the patients had 


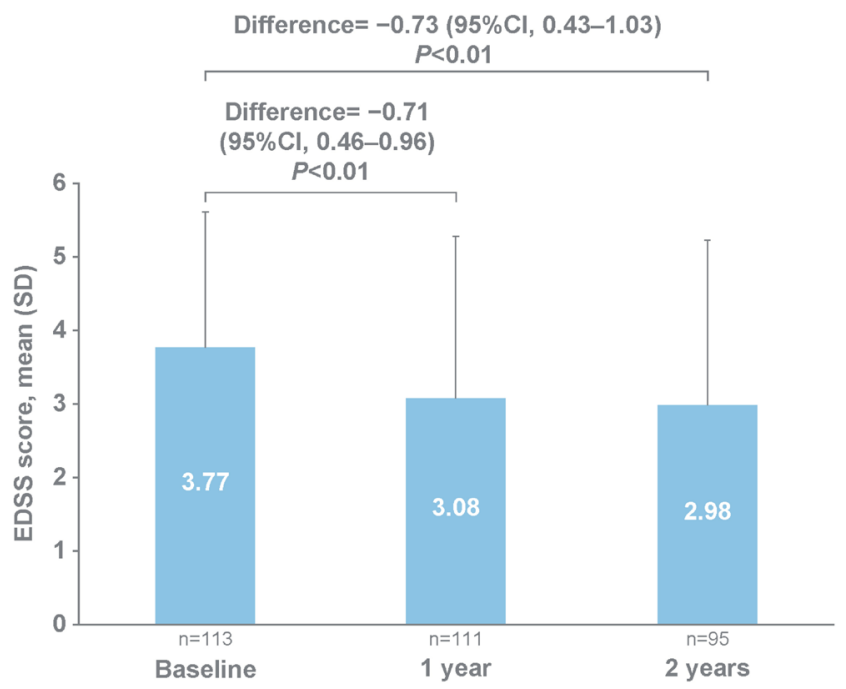

Pvalues based on paired sample t-test.

Figure 3. Mean Expanded Disability Status Scale scores at baseline, one year and two years.

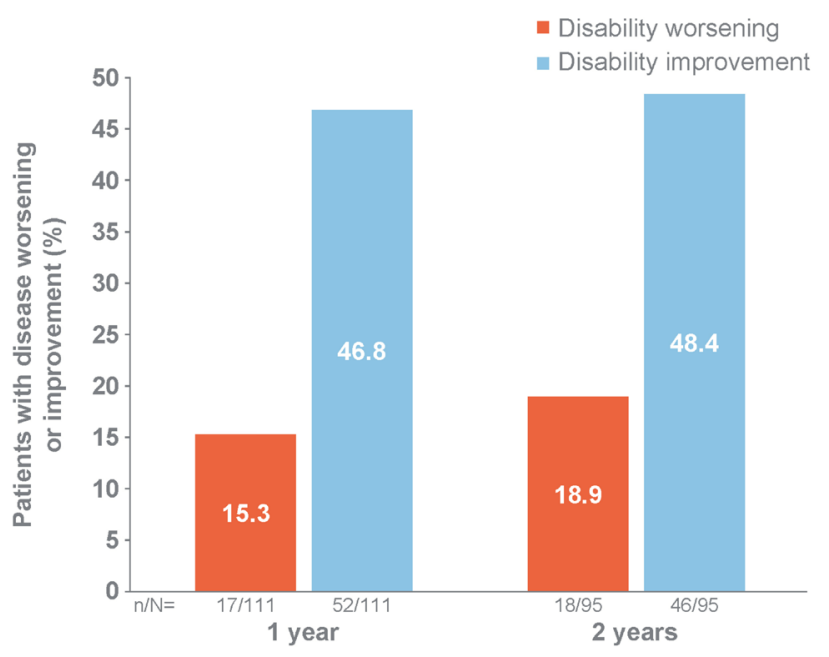

Worsening of disability was defined as any increase in EDSS score from baseline. Improvement of disability was defined as any decrease in EDSS score from baseline.

Figure 4. Proportions of patients with worsening and improvement of disability at one year and two years. no new $\mathrm{Gd}+$ lesions and $87.8 \%$ had no new or newly enlarging T2 lesions.

\section{DISCUSSION}

The findings observed in this study on real-world evidence, which was carried out in Argentina and Chile, were consistent with data from previous studies on natalizumab conducted in other regions. We observed that natalizumab was effective over a two-year period in terms of disease activity, measured by reduced relapse rate, stable EDSS and reductions in new or enlarging MRI lesions.

Over the two-year duration of the phase 3 AFFIRM study ${ }^{4}$ on PwRMS, natalizumab monotherapy demonstrated consistent efficacy in the overall study population and across multiple subgroups of patients that had been predefined on the basis of demographic and baseline disease characteristics, including age, sex, number of brain MRI lesions, disability status and number of relapses in the prior year ${ }^{4,11}$. Nonetheless, while the AFFIRM ${ }^{4}$ trial established the safety and efficacy of natalizumab, randomized controlled trial populations may not completely represent patients treated in a clinical practice setting ${ }^{7,12}$.

Therefore, data are needed to confirm the effectiveness of natalizumab in clinical practice, particularly in our region (Latin American populations), since previous data have come principally from Europe and North America ${ }^{6,7,8}$, and there were no data on any large multicenter cohort of Latin American patients, who would be expected to present differences in comparison with patients from these other regions. Many studies seeking real-world evidence have been and are being published, which are providing valuable information on natalizumab effectiveness in different clinical practice scenarios ${ }^{7}$. However, not all of them use the same outcome measurements.

In this regard, the Tysabri Observational Program (TOP) is an ongoing, open-label, multinational, multicenter, prospective, observational study conducted in Europe, Australia,

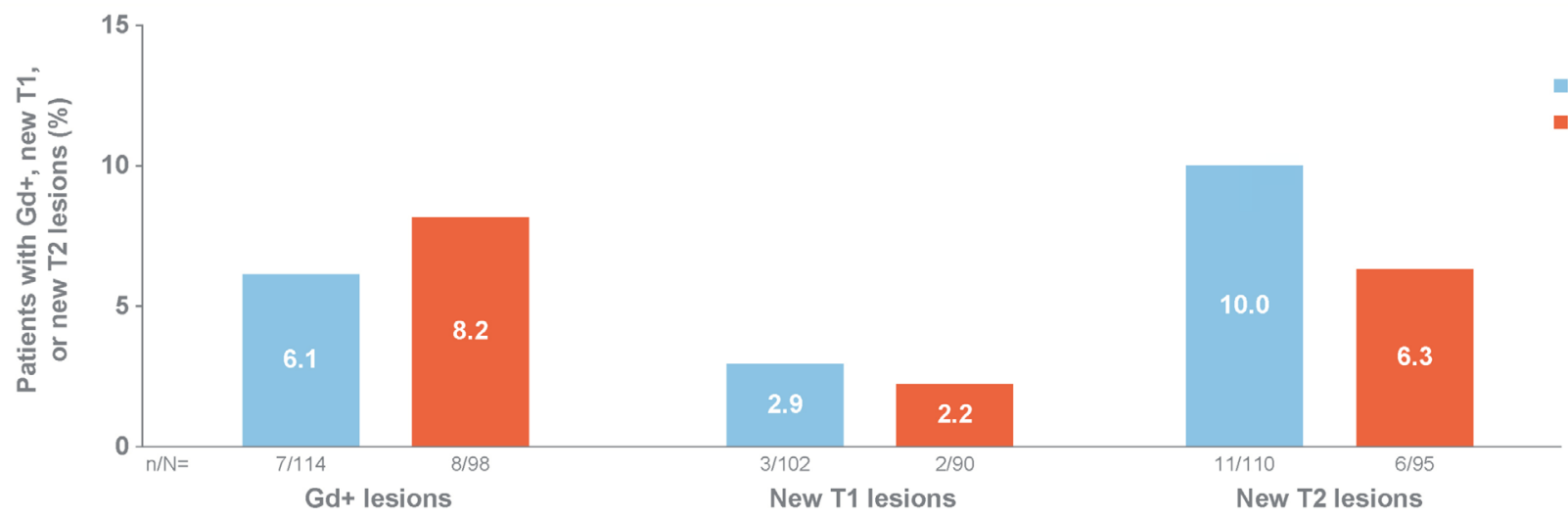

Figure 5. Patients with MRI activity after one year and two years of natalizumab treatment. 
Canada and Argentina ${ }^{8}$. Its results provide information on the long-term safety of natalizumab and its impact on ARR and EDSS progression in PwRMS after up to 10 years of treatment $^{13}$. Unfortunately, it gives no data on MRI parameter outcomes. Unlike the AFFIRM population, in which the majority of the patients were treatment-naïve ${ }^{4}$, the majority of the patients in TOP (about 90\%) and those in our study (75\%) had been previously treated with a DMT and/or immunosuppressant therapy. Consistent with other studies from Europe and North America (ARR between 1.3 and 2.5) 14,15,16,17,18,19,20,21,22 ,23,24,25,26,27,28,29,30,31 , the mean number of relapses prior to natalizumab treatment initiation was similar between our patient population (2.0) and the TOP study (1.99) ${ }^{8}$, and considerably higher than the number among patients receiving natalizumab in the AFFIRM study $(1.53)^{4}$. We found a similar situation in comparing the baseline EDSS scores between these populations: the mean baseline EDSS score among AFFIRM patients was $2.3^{4}$, while in TOP and our study population the scores were $3.5^{8}$ and 3.7 , respectively. In addition, ranges from 3.7 to 4.8 were also reported in a review of observational studies $^{7}$. These differences gain importance in everyday practice and should be taken into consideration, given that quite often patients in clinical settings do not match those studied in the pivotal trials.

In the present study, we observed that treatment with natalizumab significantly reduced the number of relapses at one and two years (93.9 and 92.9\%, respectively). This was comparable with the $90.7 \%$ reduction in ARR achieved in $\mathrm{TOP}^{32}$ and $83.2 \%$ in a recently published study in the US ${ }^{6}$, as well as in other observational studies $^{14,15,16,17,18,19,20,21,22,23,24,25,26,27,28,29,30,31}$. In addition, the TOP study reported that PwRMS treated with natalizumab presented associations with reductions in relapse-related hospitalizations and steroid treatment, despite longer follow-up in the on-natalizumab period than in the pre-natalizumab period $^{33}$. In this regard, PwRMS treated with natalizumab in Argentina and Chile experienced significant reductions in relapse-related hospitalizations at one and two years. A real-life study on a Swiss cohort ${ }^{20}$ demonstrated that the effect of natalizumab on ARR reduction not only depended on disease activity at baseline, but also was effective in PwRMS after a long period of active disease (one and two years before baseline), thus suggesting that natalizumab presented sustained efficacy that was not derived from bias concerning the evaluation of baseline data.

Regarding disability, we observed that the decrease in EDSS score was greater than what was reported in Europe $^{21,26,30}$, but lower than the results achieved in a study in Kuwait $^{34}$. In addition, observational studies ${ }^{7,26,27,28,29,30,31,32,33,34,35}$ have reported that between 9 and 57\% of PwRMS experienced improvement of disability, while $4-17 \%$ had worsening of disability, which is consistent with our results. In this regard, a post hoc analysis within AFFIRM reported that PwRMS treated with natalizumab increased their cumulative likelihood of 12-week confirmed improvement of disability, compared with placebo at two years ${ }^{36}$.

When the MRI endpoints were analyzed, we found robust decreases in all parameters of disease activity. Similar to our results, the findings from other cohorts showed that the mean number of $\mathrm{Gd}+$ lesions was reduced by $78-93.1 \% \%^{6,21,28}$ after natalizumab treatment compared with pre-natalizumab, and no new or enlarging T2 lesions was reported in up to $95 \%^{21}$. Combination of these clinical and radiological outcomes resulted in a high proportion $(65.5 \%)$ of patients reaching NEDA at two years. A recently published study (STRIVE study) ${ }^{6}$ reported that $44.4 \%$ of PwRMS who started natalizumab treatment early exhibited overall NEDA at two years. In addition, similar results (33-63\%) $)^{14,15,16,17,18,21,28,35}$ have been found in other real-world observational studies after mean follow-ups ranging from 1.3 to 2 years.

The present study had some limitations. It was a retrospective study with possible selection bias. Although careful data collection and patient follow-up were developed in each center, to decrease the possibility of potential information bias, there were some missing data. Additionally, when EDSS scores were collected, any change regardless of magnitude was counted as worsening or improvement and without confirmation; therefore, these results should be interpreted accordingly. In addition, we included relatively small numbers of patients in this analysis, with a lack of randomization and no internal comparator or control group. The patients included were from main MS centers of both countries, which may have generated an analysis bias. Lastly, although this was a cohort from two countries, it may not reflect the entire Latin American population.

Despite these limitations, the results from our study highlight the consistent effectiveness of natalizumab in clinical practice settings and provide local information in a cohort of Argentinean and Chilean patients. This study, along with TOP and other observational registries of natalizumab-treated patients ${ }^{6,7,15}$, will continue to generate valuable data on the long-term safety and effectiveness profile of natalizumab. These data will help in real-life decision-making when choosing the best treatment option for our patients.

\section{ACKNOWLEDGEMENTS}

The authors would like to acknowledge the EveRest study co-investigators including Drs. Fiol, Gaitán, Lopez, Carnero Contentti, Pettinicchi, Povedano, Tizio, Villa, Fracaro, Rey, Saladino, Deri, Parisi, Jacobo, José and Questa Laudani for their contributions. The authors would like to acknowledge Dr. Criniti Juan Martin (Hospital Alemán de Buenos Aires) for his expert assistance with statistical analysis and interpretation. 
1. Polman, $\mathrm{CH}$, Reingold, SC., Banwell, B, Clanet M, Cohen JA, Filippi $M$, et al. Diagnostic criteria for multiple sclerosis: 2010 revisions to the McDonald criteria. Ann Neurol. 2011 Feb;69(2):292-302. https:// doi.org/10.1002/ana.22366

2. Cristiano E, Patrucco L, Rojas JI. A systematic review of the epidemiology of multiple sclerosis in South America. Eur $J$ Neurol. 2008 Dec;15(12):1273-8. https://doi.org/10.1111/j.14681331.2008.02330.x

3. Cristiano E, Patrucco L, Miguez J, Giunta D, Correale J, Fiol M, et al. Increasing prevalence of multiple sclerosis in Buenos Aires, Argentina. Mult Scler Relat Disord. 2016 Sep;9:91-4. https://doi. org/10.1016/j.msard.2016.07.007

4. Tysabri label in Argentina [accessed on Apr 10, 2017]. Available at: http://www.anmat.gov.ar/boletin_anmat/Abril_2017/ Dispo_3395-17.pdf

5. Tysabri label in Chile [accessed on Oct 15, 2014]. Available at: http:// www.ispch.cl/sites/default/files/tysabri_300mg_15ml.pdf

6. Perumal J, Fox RJ, Balabanov R, Balcer LJ, Galetta S, Makh S, et al. Outcomes of natalizumab treatment within 3 years of relapsingremitting multiple sclerosis diagnosis: a prespecified 2-year interim analysis of STRIVE. BMC Neurol. 2019 Jun;19(1):116. https://doi. org/10.1186/s12883-019-1337-z

7. van Pesch V, Sindic CJ, Fernández O. Effectiveness and safety of natalizumab in real-world clinical practice: Review of observational studies. Clin Neurol Neurosurg. 2016 Oct;149:55-63. https://doi. org/10.1016/j.clineuro.2016.07.001

8. Butzkueven H, Kappos L, Pellegrini F, Trojano M, Wiendl H, Patel RN, et al. Efficacy and safety of natalizumab in multiple sclerosis: interim observational programme results. J Neurol Neurosurg Psychiatry. 2014 Nov;85(11):1190-7. https://doi.org/10.1136/jnnp-2013-306936

9. Kurtzke JF. Rating neurologic impairment in multiple sclerosis. An expanded disability status scale (EDSS). Neurology. 1983 Nov;33(11):1444-52. https://doi.org/10.1212/wnl.33.11.1444

10. Havrdova E, Galetta S, Hutchinson M, Stefoski D, Bates D, Polman $\mathrm{CH}$, et al. Effect of natalizumab on clinical and radiological disease activity in multiple sclerosis: a retrospective analysis of the Natalizumab safety and efficacy in relapsing-remitting multiple sclerosis (AFFIRM) study. Lancet Neurol. 2009 Mar;8(3):254-60. https://doi.org/10.1016/S1474-4422(09)70021-3

11. Hutchinson M, Kappos L, Calabresi PA, Confavreux C, Giovannoni G, Galetta SL, et al. The efficacy of natalizumab in patients with relapsing multiple sclerosis: subgroup analyses of AFFIRM and SENTINEL. J Neurol. 2009 Mar;256(3):405-15. https://doi. org/10.1007/s00415-009-0093-1

12. Alonso R, Contentti EC, Imhoff G, Lopez PA, Rubstein A, Tizio S. Barriers against a successful MS treatment: The importance of effectiveness beyond efficacy. Mult Scler Relat Disord. 2019 May;30:129-135. https://doi.org/10.1016/j.msard.2019.01.056

13. Kappos, L., Butzkueven, H., Spelman, T., Trojano, M., Wiendl, H., Jiang, X., et al. Real-world data from over 10 years in the TYSABRI ${ }^{\circledR}$ Observational Program: Long-term safety and effectiveness of natalizumab in relapsing-remitting multiple sclerosis patients. Rev Neurol. 2019 Apr;175(Suppl 1):S101-S102. https://doi.org/10.1016/j. neurol.2019.01.271

14. Krysko KM, O'Connor PW. The Toronto observational study of natalizumab in multiple sclerosis. Can J Neurol Sci. 2011 May;38(3):422-8. https://doi.org/10.1017/s0317167100011811

15. Correia I, Batista S, Galego O, Marques IB, Jesus-Ribeiro J, Martins Al, et al. Long-term effectiveness and safety of natalizumab in a Portuguese population. Int Immunopharmacol. 2017 May;46:105-11. https://doi.org/10.1016/j.intimp.2017.03.006

16. Outteryck O, Ongagna JC, Zéphir H, Fleury MC, Lacour A, Blanc F, et al. Demographic and clinic characteristics of French patients treated with natalizumab in clinical practice. J Neurol. 2010 Feb;257(2):20711. https://doi.org/10.1007/s00415-009-5294-0

17. Melin A, Outteryck O, Collongues N, Zéphir H, Fleury MC, Blanc F, et al. Effect of natalizumab on clinical and radiological disease activity in a French cohort of patients with relapsing-remitting multiple sclerosis. J Neurol. 2012 Jun;259(6):1215-21. https://doi. org/10.1007/s00415-011-6339-8

18. Outteryck O, Ongagna JC, Brochet B, Rumbach L, Lebrun-Frenay C, Debouverie $\mathrm{M}$, et al. A prospective observational post-marketing study of natalizumab-treated multiple sclerosis patients: clinical, radiological and biological features and adverse events. The BIONAT cohort. Eur J Neurol. 2014;21(1):40-8. https://doi.org/10.1111/ene.12204

19. Weinstock-Guttman B, Galetta SL, Giovannoni G, Havrdova E, Hutchinson M, Kappos L, et al. Additional efficacy endpoints from pivotal natalizumab trials in relapsing-remitting MS. J Neurol. 2012 May;259(5):898-905. https://doi.org/10.1007/s00415-011-6275-7

20. Kallweit U, Jelcic I, Braun N, Fischer H, Zörner B, Schreiner B, et al. Sustained efficacy of natalizumab in the treatment of relapsingremitting multiple sclerosis independent of disease activity and disability at baseline: real-life data from a Swiss cohort. Clin Neuropharmacol. 2012 Mar-Apr;35(2):77-80. https://doi.org/10.1097/ WNF.0b013e31824644e6

21. Putzki N, Yaldizli O, Bühler R, Schwegler G, Curtius D, Tettenborn B. Natalizumab reduces clinical and MRI activity in multiple sclerosis patients with high disease activity: results from a multicenter study in Switzerland. Eur Neurol. 2010;63(2):101-6. https://doi. org/10.1159/000276400

22. Holmén C, Piehl F, Hillert J, Fogdell-Hahn A, Lundkvist M, Karlberg E, et al. A Swedish national post-marketing surveillance study of natalizumab treatment in multiple sclerosis. Mult Scler. 2011 Jun;17(6):708-19. https://doi.org/10.1177/1352458510394701

23. Oturai AB, Koch-Henriksen N, Petersen T, Jensen PE, Sellebjerg F, Sorensen PS. Efficacy of natalizumab in multiple sclerosis patients with high disease activity: a Danish nationwide study. Eur J Neurol. 2009 Mar;16(3):420-3. https://doi.org/10.1111/j.14681331.2008.02517.x

24. Belachew S, Phan-Ba R, Bartholomé E, Delvaux V, Hansen I, Calay $P$, et al. Natalizumab induces a rapid improvement of disability status and ambulation after failure of previous therapy in relapsingremitting multiple sclerosis. Eur J Neurol. 2011 Feb;18(2):240-5. https://doi.org/10.1111/j.1468-1331.2010.03112.x

25. Mancardi GL, Tedeschi G, Amato MP, D’Alessandro R, Drago F, Milanese C, et al. Three years of experience: the Italian registry and safety data update Neurol Sci. 2011 Jan;31 Suppl 3:295-7. https:// doi.org/10.1007/s10072-010-0356-8

26. Totaro R, Lugaresi A, Bellantonio P, Danni M, Costantino G, Gasperini C, et al. Natalizumab treatment in multiple sclerosis patients: a multicenter experience in clinical practice in Italy. Int J Immunopathol Pharmacol. 2014 Apr-Jun;27(2):147-54. https://doi. org/10.1177/039463201402700201

27. Sangalli F, Moiola L, Bucello S, Annovazzi P, Rizzo A, Radaelli M, et al. Efficacy and tolerability of natalizumab in relapsing-remitting multiple sclerosis patients: a post-marketing observational study. Neurol Sci. 2011 Jan;31 Suppl 3:299-302. https://doi.org/10.1007/ s10072-010-0344-z

28. Prosperini L, Giannì C, Fubelli F, Marinelli F, Pozzilli C. Natalizumab treatment in multiple sclerosis: the experience of S. Andrea MS Centre in Rome. J Neurol Sci. 2012 Dec;323(1-2):104-12. https://doi. org/10.1016/j.jns.2012.08.027

29. Prosperini L, Giannì C, Barletta V, Mancinelli C, Fubelli F, Borriello $\mathrm{G}$, et al. Predictors of freedom from disease activity in natalizumab treated-patients with multiple sclerosis. J Neurol Sci. 2012 Dec;323(1-2):104-12. https://doi.org/10.1016/j.jns.2012.08.027 
30. Fernández O, Oreja-Guevara C, Arroyo R, Izquierdo G, Pérez JL, Montalban X. Natalizumab treatment of multiple sclerosis in Spain: results of an extensive observational study. J Neurol. 2012 Sep;259(9):1814-23. https://doi.org/10.1007/s00415-012-6414-9

31. Fernández-Megía MJ, Casanova B, Magraner MJ, Font-Noguera I, Poveda-Andrés JL. Assessment of the effectiveness and safety of natalizumab for treating relapsing-remitting multiple sclerosis. Farm Hosp. 2011 Mar-Apr;35(2):75-9. https://doi.org/10.1016/j. farma.2010.02.003

32. van Pesch V, Bartholomé E, Bissay V, Bouquiaux O, Bureau M, Caekebeke J, et al. Safety and efficacy of natalizumab in Belgian multiple sclerosis patients: subgroup analysis of the natalizumab observational program. Acta Neurol Belg. 2014 Sep;114(3):167-78. https://doi.org/10.1007/s13760-014-0308-9

33. Trojano M, Spelman T, Butzkueven H, Kappos L, Wiendl H, Chang I, et al. Natalizumab is associated with a reduction in relapse-related hospitalisations and steroid treatment in relapsing-remitting multiple sclerosis patients enrolled in the TYSABRI ${ }^{\circledast}$ Observational Program. ECTRIMS Online Library. Trojano M. 10/10/18; 228441; P597.

34. Alroughani R, Al Hashel J, Thussu A, Ahmed SF. Use of natalizumab in patients with active relapsing-remitting multiple sclerosis in Kuwait. Med Princ Pract. 2013;22(5):495-9. https://doi. org/10.1159/000351568

35. Fernández O, Alvarenga MP, Guerrero M, León A, Alonso A, LópezMadrona JC, et al. The efficacy of natalizumab in patients with multiple sclerosis according to level of disability: results of an observational study. Mult Scler. 2011 Feb;17(2):192-7. https://doi. org/10.1177/1352458510385507

36. Phillips JT, Giovannoni G, Lublin FD, O'Connor PW, Polman CH, Willoughby $\mathrm{E}$, et al. Sustained improvement in expanded disability status scale as a new efficacy measure of neurological change in multiple sclerosis: treatment effects with natalizumab in patients with relapsing multiple sclerosis. Mult Scler. 2011 Aug;17(8):970-9. https://doi.org/10.1177/1352458511399611 